\title{
Therapeutic knee taping improved pain and disability in osteoarthritis of the knee
}

Hinman RS, Crossley KM, McConnell J, et al. Efficacy of knee tape in the management of osteoarthritis of the knee: blinded randomised controlled trial. BMJ 2003;327:135-8.

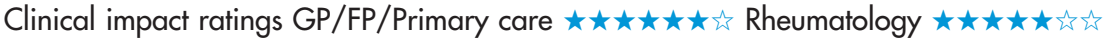

\section{In patients with osteoarthritis (OA) of the knee, does therapeutic knee taping (TKT) reduce pain and disability?} METHODS

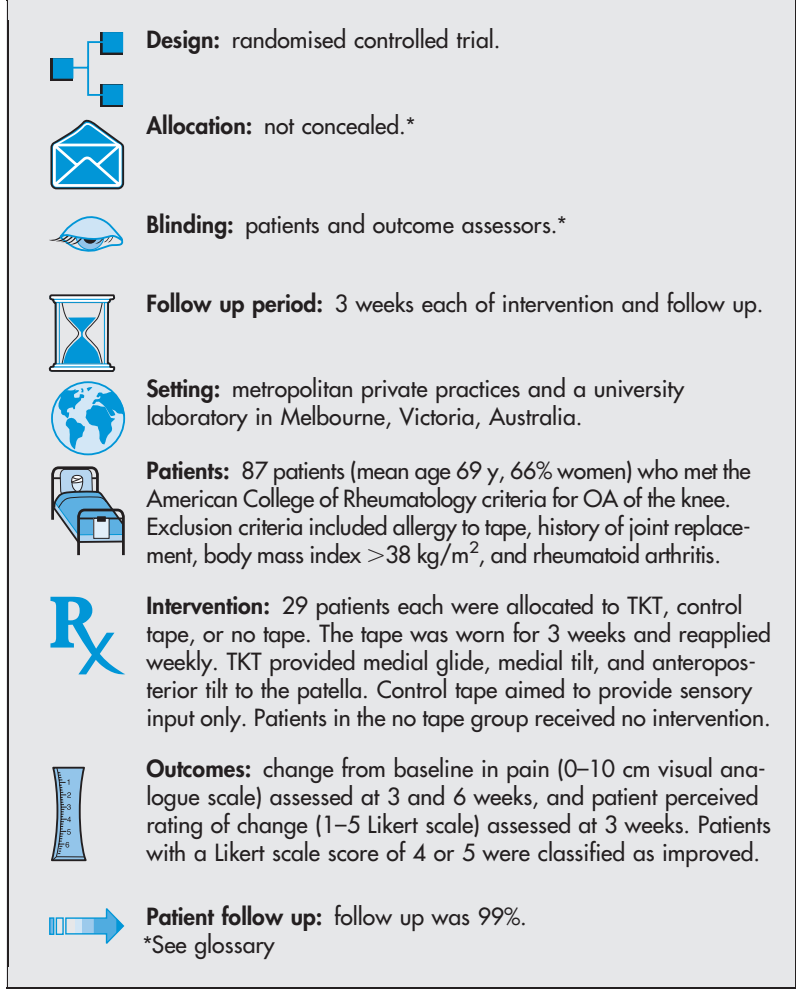

\section{MAIN RESULTS}

Analysis was by intention to treat. The table shows the 3-week results. At 6 weeks, reduction in pain on worst activity was greater in the TKT group than in the no tape or control group ( $\mathrm{p}<0.05$ for both), whereas reduction in pain on movement was only greater in the TKT group than in the no tape group $(\mathrm{p}<0.05)$.

For correspondence: Dr R S Hinman, University of Melbourne, Melbourne Victoria, Australia. ranash@unimelb.edu.au

Sources of funding: National Health and Medical Research Council and Australia New Zealand Charitable Trusts.

\section{CONCLUSION}

In patients with osteoarthritis of the knee, therapeutic knee taping improved pain and disability.

Abstract and commentary also appear in ACP Journal Club.

\section{Commentary}

B ecause no cure for $\mathrm{OA}$ exists, treatments focus on managing symptoms so that individuals can maintain reasonable functional capabilities. The overwhelming preponderance of treatments evaluated for OA are drugs (60\% of treatment studies) or surgical procedures $(26 \%)$, with a remarkable neglect of physical treatment methods. ${ }^{1}$

The randomised controlled trial by Hinman et al highlights the importance of the patellofemoral joint as source of symptoms in knee $\mathrm{OA}$. Although the American College of Rheumatology recommended taping osteoarthritic knees for years before this trial, evidence to show that it works in reducing pain has been minimal.

This study shows that TKT reduces pain and disability in patients with knee OA. The influence of the tape may "unload" the lateral patellofemoral joint where pathology and resultant symptoms predominate. The beneficial effects were maintained 3 weeks after the treatment was stopped. The magnitude of the treatment effect of taping was that of drug therapies and exercise programmes.

The treatment was well tolerated and safe. $28 \%$ of patients in the TKT group compared with 1 patient $(3 \%)$ in the control tape group reported minor skin irritation. Even so, all participants continued to wear their tape for 3 weeks.

Some study limitations exist: Firstly, the TKT group had greater pain scores at baseline, raising concerns about imbalanced randomisation of participants. Secondly, because the treating therapist could influence by verbal suggestion the subjective outcome of pain, blinding may not have been optimal. Thirdly, a number of potential concerns with wider generalisability and application of the results exist. It should be noted that the tape was applied by physical therapists trained in assessment and application of this technique, and the Australian population studied was not as obese as many OA patient groups in the US. However, TKT may offer a simple and effective self management strategy for knee OA. David Hunter, MD, PhD David Felson, MD, MPH Boston University School of Medicine Boston, Massachusetts, USA

1 Tallon D, Chard J, Dieppe P. Relation between agendas of the research community and the research consumer. Lancet 2000;355:2037-40.

Therapeutic knee taping (TKT) $v$ control tape (CTP) or no tape (NTP) in osteoarthritis of the knee at 3 weeks*

\begin{tabular}{|c|c|c|c|c|}
\hline Outcomes & Comparisons & Mean scores & Difference between $\mathrm{g}$ & $\%$ Cll $\dagger$ \\
\hline \multirow{3}{*}{$\begin{array}{l}\text { Change from baseline in pain on movement } \\
\text { (VAS) } \\
\text { Change from baseline in pain on worst } \\
\text { activity (VAS) }\end{array}$} & TKT $v$ NTP & $-2.1 \vee 0.1$ & $2.1(1.2$ to 3.0$)$ & \\
\hline & TKT $v$ CTP & $-2.1 v-0.7$ & $1.3(0.3$ to 2.4$)$ & \\
\hline & TKT $v$ CTP & $-2.5 v-1.1$ & $1.5(0.3$ to 2.7$)$ & \\
\hline & & Event rates & $\mathrm{RBI}(\mathrm{Cl})$ & NNT (Cl) \\
\hline Proportion of patients improved & $\begin{array}{l}\text { TKT } v \text { NTP } \\
\text { TKT } v \text { CTP }\end{array}$ & $\begin{array}{l}72 \% \text { v } 10 \% \\
72 \% \vee 48 \%\end{array}$ & $\begin{array}{l}600 \%(164 \text { to } 1960) \\
50 \%(-1.7 \text { to } 140)\end{array}$ & $\begin{array}{l}2(2 \text { to } 3) \\
\text { Not significant }\end{array}$ \\
\hline
\end{tabular}

*VAS $=0-10 \mathrm{~cm}$ visual analogue scale. Other abbreviations defined in glossary; RBI, NNT, and $\mathrm{Cl}$ calculated from data in article.

tSignificant differences favour TKT (round off errors increase or decrease difference by 0.1 ). 